\title{
ANALOGIAS PARA O ENSINO DE BIOQUÍMICA NO NÍVEL MÉDIO
}

\author{
Jéssica Ulisses Barbosa* \\ Murilo Cruz Leal** \\ Samuel Quinaud Rossi*** \\ Tamara Nayara Dias**** \\ Karla Aparecida Ferreira***** \\ Cristiane Pereira de Oliveira ${ }^{* * * * *}$
}

RESUMO: O artigo tem como objetivos apresentar uma proposta de abordagem de temas de Bioquímica no Ensino Médio por meio de analogias, bem como avaliar a pertinência dessa proposta a partir de comentários escritos dos estudantes. O projeto "ExpoBiochimica: Compreendendo Fenômenos Bioquímicos por Meio de Analogias" foi desenvolvido na Universidade Federal de São João del-Rei (UFSJ). A apresentação dos temas bioquímicos associados a sistemas analógicos cotidianos deu-se por meio de painéis. O material produzido, envolvendo oito temas, foi exposto em escolas públicas por alunos das licenciaturas de Ciências Biológicas e Química da UFSJ. Os comentários elaborados pelos alunos do Ensino Médio são discutidos no artigo, caracterizando uma avaliação positiva do uso de analogias para o ensinoaprendizagem de conteúdos bioquímicos.

Palavras-chave: ensino de Bioquímica, analogias, ensino médio

\section{ANALOGIES FOR TEACHING BIOCHEMISTRY IN HIGH SCHOOL}

ABSTRACT: The article aims to present a proposal for addressing issues of Biochemistry in high school by means of analogies, and assess the relevance of such a proposal from the students' written comments. The project "ExpoBiochimica: Understanding Biochemical Phenomena through Analogies " was developed at the Federal University of São João del-Rei (UFSJ). The presentation of the issues associated with biochemical analog was given daily through dashboards. The material produced, involving eight subjects was exposed in public schools by the undergraduate students of Biological Sciences and Chemistry UFSJ. The comments made by high school students are discussed in the article, featuring a positive evaluation of the use of analogies for teaching and learning of biochemical content.

Key-words: Biochemistry teaching, analogies, high school

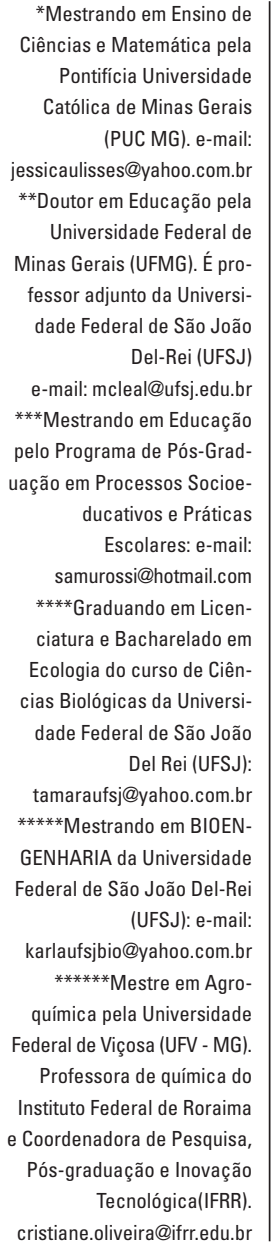

*Mestrando em Ensino de Ciências e Matemática pela Pontifícia Universidade Católica de Minas Gerais (PUC MG). e-mail: jessicaulisses@yahoo.com.br **Doutor em Educação pela Universidade Federal de Minas Gerais (UFMG). É professor adjunto da Universidade Federal de São João Del-Rei (UFSJ)

e-mail: mcleal@ufsj.edu.br ***Mestrando em Educação pelo Programa de Pós-Graduação em Processos Socioeducativos e Práticas Escolares: e-mail: samurossi@hotmail.com ****Graduando em Licenciatura e Bacharelado em Ecologia do curso de Ciências Biológicas da Universidade Federal de São João Del Rei (UFSJ):

tamaraufsj@yahoo.com.br ***** Mestrando em BIOENGENHARIA da Universidade Federal de São João Del-Rei (UFSJ): e-mail:

karlaufsjbio@yahoo.com.br

******Mestre em Agroquímica pela Universidade Federal de Viçosa (UFV - MG).

Professora de química do Instituto Federal de Roraima e Coordenadora de Pesquisa, Pós-graduação e Inovação Tecnológica(IFRR).

cristiane.oliveira@ifrr.edu.br 
Jéssica U1isses Barbosa|Murilo Cruz Leal|Samue1 Quinaud Rossi|

Tamara Nayara Dias|Karla Aparecida Ferreira| Cristiane Pereira de Oliveira

\section{INTRODUÇÃO}

Imagens, analogias e metáforas são recursos que podem ser amplamente utilizados pelos professores em salas de aula para a comunicação de ideias científicas (HOFFMANN e SCHEID, 2007; MARTINS et al., 2005; PERRELLI, 1994). Há algum tempo, esses recursos e a importância do seu papel na vida acadêmica dos alunos têm sido objeto de investigações no campo da educação em ciências (ANDRADE et al., 2000; DUARTE, 2005; FERRAZ e TERRAZAN, 2003; HOFFMANN e SCHEID, 2007; MARTINS et al., 2005; PÁDUA, 2010). $\mathrm{Na}$ história da ciência, podemos encontrar algumas analogias para o entendimento de fenômenos não observáveis (CARMO, 2006; SILVA e TERRAZAN, 2005), como é o caso de Thompson, que propõe, para a explicação de seu modelo atômico, uma analogia com um pudim de passas (SILVA e TERRAZAN, 2005).

A analogia não pressupõe igualdade simétrica, mas uma relação usada com a finalidade de esclarecer o desconhecido a partir do que se conhece (DUARTE, 2005; HOFFMANN e SCHEID, 2007). Dessa forma, a analogia pode ser definida como uma comparação entre dois domínios que asseguram algumas correlações (CARMO, 2006; DUARTE, 2005; MONTEIRO e JUSTI, 2000). Sendo assim, há dois domínios: o análogo, o qual representa o conhecimento familiar aos alunos, e o alvo, que representa o conhecimento desconhecido ou menos familiar (MENDONÇA et al., 2005; MONTEIRO e JUSTI, 2000). Desses domínios, surgem as relações analógicas que correspondem às relações que podem ser efetuadas e estabelecidas, sejam elas de semelhança ou de diferença, entre o alvo e o analógico (SILVA e TERRAZAN, 2005).

Convictos da importância e cientes da consagrada presença (não sem problemas) de analogias na educação científica, bem como na construção das ciências, apresentamos neste artigo uma proposta de abordagem de temas de Bioquímica no ensino médio por meio desse tipo de comparação - o projeto "ExpoBiochimica: Compreendendo Fenômenos Bioquímicos por Meio de Analogias" -, bem como uma avaliação da pertinência dessa proposta a partir de comentários escritos dos estudantes.

\section{Analogia como estratégia de ensino-aprendizagem em Ciências}

De acordo com Monteiro e Justi (2000), as analogias são modelos de ensino que podem atuar como mediadoras no processo de ensino-aprendizagem. Segundo Duit (1991), as analogias podem ser instrumentos importantes na construção do conhecimento, pois atuam no processo de associações entre o estranho e o familiar, levando o sujeito a reestruturar informações prévias ou formar novos esquemas cognitivos. Assim, elas subsidiam o processo de aprendizagem significativa. Como indica Moreira, 
$\mathrm{Na}$ aprendizagem significativa há uma interação entre o novo conhecimento e o já existente, na qual ambos se modificam. À medida que o conhecimento prévio serve de base para a atribuição de significados à nova informação, ele também se modifica [...] adquirindo novos significados, se tornando mais diferenciados, mais estáveis. A estrutura cognitiva está constantemente se reestruturando durante a aprendizagem significativa. $\mathrm{O}$ processo é dinâmico; o conhecimento vai sendo construído (MOREIRA, 1997, p.5).

O uso de analogias no ensino de Ciências de forma geral tem sido importante para esclarecer e facilitar a aprendizagem de conceitos científicos (CARMO, 2006; FIGUEROA et al., 2003; NUNES et al., 2009). Embora existam resultados positivos, não devemos deixar de considerar as críticas fundamentadas no trabalho epistemológico de Gaston Bachelard, que refuta certos mecanismos da educação não formal, como o uso de metáforas, animismos, analogias, experiências cotidianas que lhe parecem empobrecer o discurso científico, constituindo obstáculos epistemológicos (ANDRADE et al., 2000). Nessa perspectiva, essas "concepções alternativas" ou formas de raciocínio pré ou não científicas denotariam um erro do ensino, sugerindo até mesmo uma estagnação ou regressão no progresso da ciência. Mendonça et al. (2005) e Figueroa et al. (2003) ressaltam que muitos autores de livros didáticos fazem pouco uso de analogias ou, quando o fazem, desconsideram as dificuldades que os alunos podem apresentar para efetuar as devidas ressalvas e limitações entre o domínio analógico e o desconhecido. Em nossa compreensão, o uso de analogias comuns ao cotidiano dos estudantes, além de estimular a reflexão sobre a lógica dos sistemas, favorecendo uma compreensão mais efetiva do tema em estudo, torna as aulas diversificadas e motivadoras. A utilização desse recurso deve acompanhar-se da explicitação das relações e conceitos científicos que estão sendo destacados, bem como das limitações do processo de comparação dos dois domínios; sem tal explicitação, os estudantes podem se prender a aspectos indesejáveis ou sem interesse do sistema analógico (CARMO, 2006; MONTEIRO e JUSTI, 2000).

\section{A Educação em Bioquímica e o ensino médio}

De acordo com Loguercio et al. (2007), a década de 90 foi marcada por uma grande proliferação de estudos e trabalhos que trouxeram para o cenário da educação um novo campo do saber: a Educação em Bioquímica. Segundo estes autores, a Educação em Bioquímica apresenta, por um lado, a tendência a resolver os problemas específicos do ensino em Bioquímica e, por outro, se preocupa com a forma de se manter uma pesquisa científica de qualidade (LOGUERCIO et al.,2007). A Bioquímica usa bastante a abstração e a imaginação para descrever os fenômenos que acontecem em nível molecular, e é difícil representar seus fenômenos somente com o auxílio dos instrumentos mais amplamente usados no cotidiano escolar, o quadro negro e o retroprojetor (MACHADO et al., 2010). Assim, faz-se necessária uma sistemática busca e aplicação de pesquisas a fim de 
propor alternativas metodológicas, com o uso de softwares educativos e da internet como ferramentas de ensino, que qualifiquem e tornem acessível a aprendizagem de Bioquímica nos vários níveis de ensino (LOGUERCIO et al., 2007).

Segundo Ana Lúcia Freitas, em uma entrevista concedida ao Centro de Biotecnologia Molecular Estrutural (CBME) da USP,

o ensino de Bioquímica no Ensino Médio é muito discreto - diria até que essa disciplina, como tal, não é apresentada aos alunos e os conceitos bioquímicos são apresentados em tópicos de Química ou de Biologia. O próprio professor não tem consciência disso, portanto não esclarece ou situa os temas apresentados. Quanto ao aprendizado, sempre o avalio como sendo superficial (FREITAS, 2006, p.1).

Freitas (2006) acredita que a utilização de laboratórios no Ensino Médio e Fundamental, bem como a exploração de trabalhos científicos na forma de peças teatrais, pode favorecer decisivamente o entendimento de temas bioquímicos. Nessa mesma direção, organizamos situações de uso de analogias com sistemas cotidianos.

\section{Projeto ExpoBiochimica}

As analogias desenvolvidas para o projeto ExpoBiochimica, executado nos anos de 2005 e 2006, baseiam-se em relações de estrutura-função comuns em nosso dia-a-dia que guardam similaridades com dinâmicas próprias do universo bioquímico. Os oito painéis didáticos produzidos e utilizados em exposições apresentam as seguintes relações:

- o catabolismo é representado como a queima de uma vela e de combustíveis (álcool ou gasolina); e o anabolismo seria a construção de uma parede;

- as relações entre células vizinhas e meio extracelular são comparadas a uma caixa de isopor cheia de gelo, contendo frascos diversos de medicamentos, refrigerantes e iogurtes que mantêm suas identidades;

- o controle da atividade enzimática por feedback é associado ao ato de acionar e acionar novamente a torneira para se tomar água ou suco a partir de um reservatório (galão), até a sede cessar;

- o quadro de diabete é comparado à ação de um carteiro que tenta entregar sua correspondência (a insulina), mas é impedido por um cão bravo;

- a síntese de proteínas é representada pela execução de uma música a partir da partitura;

- a ação de lactobacilos no intestino é representada pela atividade de super-heróis de quadrinhos;

- a digestão intracelular é comparada ao processo de reciclagem de lixo;

- o efeito da atividade enzimática é relacionado a um percurso feito a pé ou de carro.

As analogias foram concebidas e os painéis elaborados por um grupo de 
oito alunos dos cursos de licenciatura de Ciências Biológicas e Química da UFSJ e pelo professor autor deste artigo, levando em consideração livros didáticos de Biologia e de Química para o Ensino Médio, bem como material bibliográfico destinado ao ensino de Bioquímica (em especial LENHINGER et al., 2002 e CONN E STUMPF, 1980), de Fisiologia e de Citologia para o nível superior.

A seguir, são reproduzidos dois painéis, "As Enzimas na Vida" e "Síntese de Proteínas". Buscando combinar visibilidade com facilidade de transporte e apresentação, os painéis foram confeccionados $\mathrm{com} 90 \mathrm{~cm}$ de altura por $60 \mathrm{~cm}$ de largura.

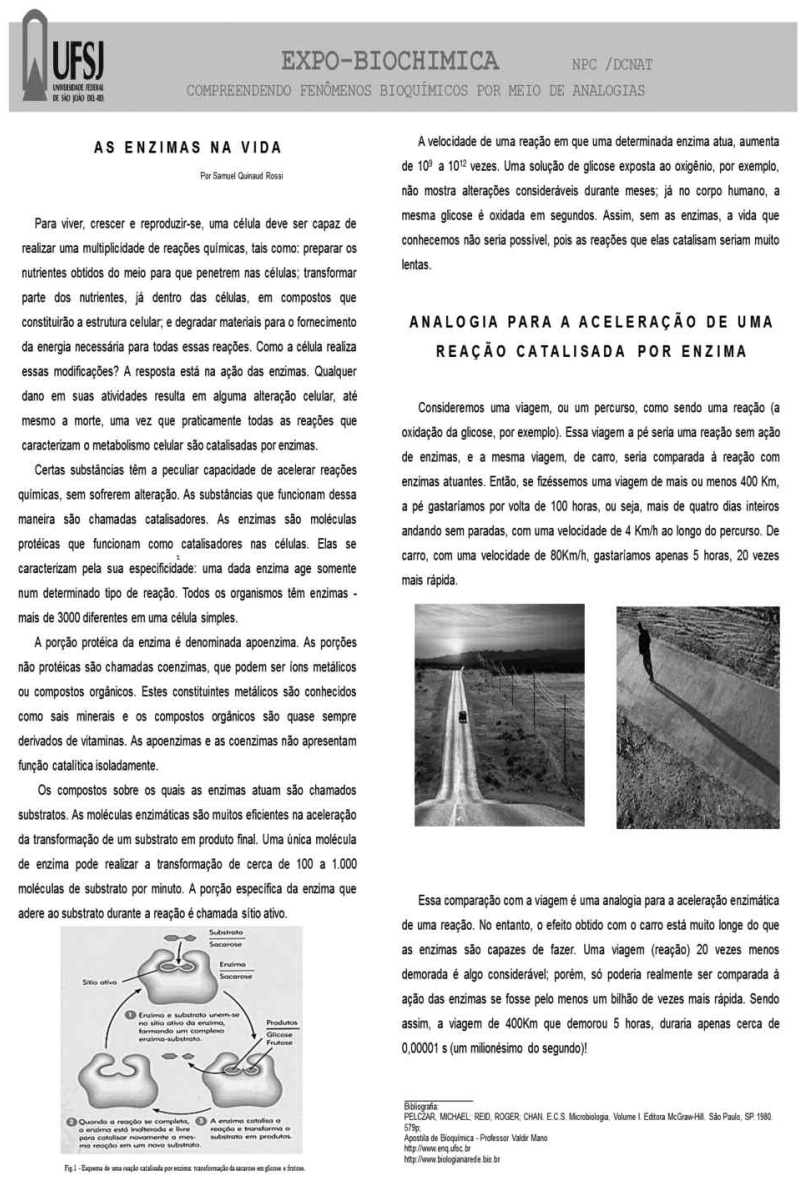


Jéssica Ulisses Barbosa|Murilo Cruz Leal| Samue1 Quinaud Rossi|

Tamara Nayara Dias | Karla Aparecida Ferreira | Cristiane Pereira de Oliveira

\section{EXPO-BIOCHIMICA NPC /DCNAT}

COMPREENDENDO EENOOMENOS BIOQUÍMICOS ROR MEIO DE ANALOGIAS

SINTESE DE PROTEINAS

Por Cistina Perera de Ohera

Proteinas sẫo compostos orgânicos macromoleculares, formados por cadeias de aminoácidos. As proteínas assumem várias funçōes nos organismos vivos: como catalisadores, elementos estruturais e contráteis; no armazenamento de nutrientes; como meio de transporte; como hormônios; e como agentes de defesa (anticorpos, toxinas). Cada proteina tem sua sequêencia especifica de aminoácidos determinada por um gene especifico (fragmento de DNA) localizado no cromossomo. 0 DNA (ácido desoxirribonucléico) è a substância responsável pela herança biológica em todos os seres vivos. A sequêencia de nucleotideos no DNA especifica a ordem de aminoácidos nas proteinas. O RNA (ácido ribonucléico) é o intermediário que transporta as informaçōes do núcleo para os ribossomos, organela celular onde ocorre a sintese proteica. Há três classes de RNA: O "RNA mensageiro" (RNAm), que leva a mensagem do DNA até os ribossomos; 0 "RNA ribossômico" (RNAr), que junto com as proteinas forma os rbossomos; e 0 "RNA transportador" (RNAt), que transporta os diversos aminoácidos até onde está ocorrendo a sintese da molécula protéica.

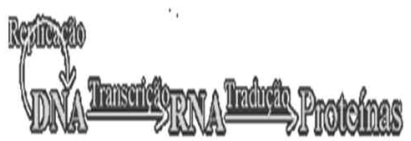

Além do DNA e do RNA, a sintese proteica envolve uma série muito grande de enzimas, aminoácidos e água. Cada aminoácido que constitui uma proteina è codificado por uma sequência de três bases nitrogenadas do RNAm (CÓDONS), denominado CÓDIGO GENÉTICO (por exemplo, GCC, corresponde à alanina).

\section{ANALOGIA PARA A SINTESE DE PROTEINAS}

0 esquema ao lado representa os três processos envolvidos na sintese de proteinas. O DNA è um "molde" para formar outro DNA idênntico (replicaçăo) e também para formar RNA (transcrição). Este, por sua vez, é o "molde" para a formação das proteinas (traduçăo). Como o RNA vem do DNA, podemos dizer que ele traz a mensagem que está guardada no núcleo das células ( no DNA, nos cromossomos) para o citossol (onde ocorre a sintese de proteinas)

Um analogia para representar a sintese de proteinas é a execução de uma música. 0 código ou informaçăo na execução de uma música seria a partitura. Os agentes ou executores sã̃o os músicos e os instrumentos, cada qual com sua função especifica. Finalmente, a música que ouvimos é o resultado de todo o processo, o que corresponderia à proteina.

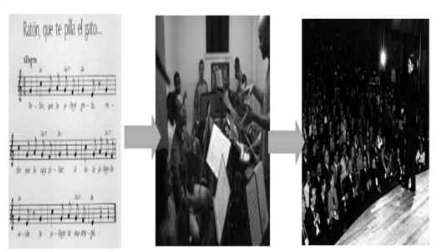

Partitura musical $\rightarrow$ músicos e instrumentos em açẵo $\rightarrow$ a música que ouvimos (DNA) (RNAs, aminoácidos, ribossomos) (proteina) Outras analogias para sintese proteica seriam: Planta de uma casa $\rightarrow$ trabahadores $e$ materiais $\rightarrow$ a casa propriamente dita; e: Definição e objetivo de uma empresa $\rightarrow$ estrutura da empresa / diferentes departamentos $\rightarrow$ produtos / serviços prestados.

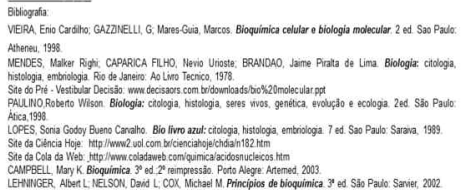

0 poster sobre síntese de proteínas foi elaborado por Murilo Cruz Leal e Cristiane Pereira de Oliveira, então graduanda da Licenciatura em Química da UFSJ e lider dos alunos do projeto na turma de 2005. 
A próxima ilustração corresponde ao conjunto de imagens e textos organizado para o painel referente à ação de lactobacilos no intestino.

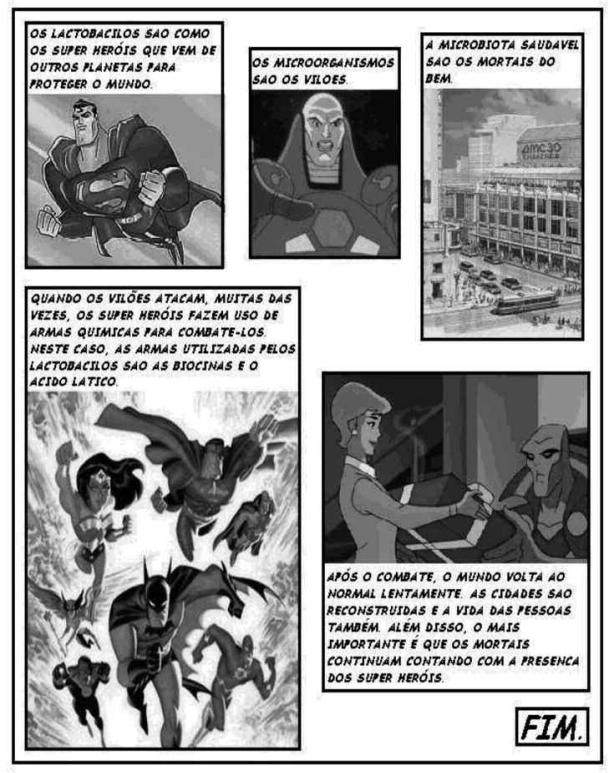

As apresentações dos painéis sobre os quais comentários de alunos são abordados neste artigo ocorreram em quatro escolas públicas do município de São João del-Rei, durante o ano de 2006. Devido à limitação de tempo nas apresentações, eram apresentados três painéis em cada sala. Os painéis aos quais se referem os comentários aqui abordados apresentam os seguintes temas: atividade de lactobacilos no intestino, digestão intracelular e atividade enzimática. Os outros temas já haviam sido apresentados no ano anterior, 2005, em escolas, encontros acadêmicos e semanas científicas. Ao final de cada apresentação, com duração de cerca de 40 minutos, era proposto que os alunos preparassem um comentário, relatando suas percepções acerca do método empregado para explicar aqueles temas: a analogia.

\section{Os comentários dos estudantes}

Um total de 262 comentários escritos foi produzido por estudantes do ensino médio, com idades entre 15 e 18 anos, referentes aos painéis e apresentações que realizamos nas escolas. Os comentários foram submetidos a análise de conteúdo, conforme proposto por Bardin (1977). No primeiro momento da análise, numa leitura inicial da totalidade dos comentários, buscamos identificar categorias temáticas recorrentes. Dado o caráter aberto da demanda e produção dos comentários, foi evitada uma predefinição na construção de categorias. 
Jéssica U1isses Barbosa|Murilo Cruz Leal|Samue1 Quinaud Rossi|

Tamara Nayara Dias | Karla Aparecida Ferreira | Cristiane Pereira de Oliveira

Os textos dos alunos encontram-se agrupados em três categorias ou blocos principais:

- o primeiro bloco reúne os comentários dos alunos em torno da percepção sobre o uso de analogias e a decorrente acessibilidade da linguagem científica através do mesmo;

- a segunda categoria congrega os excertos que expõem a analogia e sua utilização no ensino como prática integradora do conhecimento científico e seus desdobramentos na vida cotidiana;

- o terceiro bloco agrupa os trechos referentes à utilização do método especificamente nas disciplinas de Biologia e Química e suas implicações para o efetivo aprendizado das matérias bem como para a compreensão da importância de determinados fenômenos na vida.

Outras categorias, com base nos comentários dos estudantes, poderiam ser elaboradas; no entanto, para o objetivo do nosso estudo, tais produções não enriquecem o trabalho.

No primeiro bloco, composto por 96 comentários, dos quais alguns se encontram expostos a seguir, os alunos relatam suas percepções quanto à utilização de analogias no ensino dos temas propostos:

O método da analogia é interessante e positivo. Na minha opinião, a comparação nos situa dentro das matérias, facilita o entendimento.

Apresentar um domínio científico em forma de analogia é muito válido porque nem sempre entendemos os conceitos cientificos.

Achei muito criativa essa aula, assim tivemos uma visão mais ampla sobre esse assunto já estudado por nós.

Achei muito bom, pois me ensinou a entender melhor a digestão intracelular no nosso organismo.

De acordo com Lima e Vasconcelos (2006), o educador em Ciências tem sido desafiado historicamente a tornar as teorias científicas palatáveis aos alunos, tentando disponibilizá-las de forma acessível, buscando recursos e/ou metodologias que possam favorecer tal prática. Segundo Andrade et al. (2000), Caffagni e Marandino (2010) e Carmo (2006), uma das maneiras de tornar a linguagem científica mais acessível consiste no uso de algumas estratégias didáticas como as metáforas e analogias.

No segundo bloco (que soma 85 comentários, no total), os trechos ilustram a percepção dos estudantes quanto ao uso de analogias descrevendo-as como método interessante na medida que permite a explicação de conteúdos científicos ligados a situações do cotidiano, referindo-se criticamente às práticas de seus pro- 
fessores com relação ao ensino de temas bioquímicos:

[... eles (os universitários) comparam a matéria com coisas do nosso dia-a-dia e assim fica mais fácil de entender. Os professores deveriam fazer isso também.

Eu acho que seria bem mais fácil de entender a matéria se os professores aderissem essa forma de ensino.

Eles conseguiram unir coisas do nosso dia-a-dia com o funcionamento do nosso organismo. Com isso a compreensão ficou mais fácil [...].

Foram bem interessantes essas comparações feitas, pois facilitam o nosso entendimento. Se tivéssemos uma aula dessas pelo menos uma vezpor mês, na minha opinião, seria bem melhor o nosso rendimento.

Conforme argumentam Garruti e Santos (2004) e Quadrado e Ribeiro (2005), o currículo vigente na maioria das escolas caracteriza-se pela fragmentação, descontextualização e irrelevância apresentada diariamente nas práticas escolares. Isto decorreria da exposição de fenômenos isolados apresentados fora de um contexto histórico, social, político, cultural e, portanto, fora da realidade dos estudantes. É preciso que os discursos proferidos em sala de aula apresentem-se articulados a elementos que fazem parte da vida dos alunos (MARCONDES, 2002). Marco Antônio Moreira lembra que a

aprendizagem [...] sem relação com o conhecimento preexistente, é mecânica, não significativa. Na aprendizagem mecânica, o novo conhecimento é armazenado de maneira arbitrária e literal na mente do indivíduo. O que não significa que esse conhecimento é armazenado em um vácuo cognitivo, mas sim que ele não interage significativamente com a estrutura cognitiva preexistente, não adquire significados. Durante certo período de tempo, a pessoa é inclusive capaz de reproduzir o que foi aprendido mecanicamente, mas não significa nada para ela. (MOREIRA, 1997, p.5)

No terceiro bloco (composto de 63 comentários), os alunos fazem referência direta à utilização do método analógico articulado às disciplinas de Biologia, Química e/ou Bioquímica:

Eu acho que os professores, principalmente de Biologia, deviam usar analogia sim. É interessante a maneira como vocês (universitários) veem a Biologia e fazem com que a matéria não seja monótona [...].

Gostei da metodologia apresentada, porque, em minha opinião, o conteúdo fica mais explícito e objetivo. Além de ficar algo mais marcado, como se esta relação feita entre o assunto da Biologia e fatos presentes no dia-a-dia fosse mais fácil de lembrar em uma prova, um teste. 
Jéssica U1isses Barbosa|Murilo Cruz Lea1|Samue1 Quinaud Rossi|

Tamara Nayara Dias | Karla Aparecida Ferreira | Cristiane Pereira de Oliveira

Explicando-se fenômenos químicos por meio de analogia, torna-se mais fácil de se entender [...]. Processos mais complexos como o das enzimas podem ser entendidos facilmente por meio da analogia.

Achei um método bem mais fácil de compreender os fenômenos bioquimicos através da analogia, e talvez a analogia poderia nos ajudar a compreender muitas outras coisas que tornam difíceis em nossas vidas.

Segundo Krasilchik (2004), a Biologia pode ser uma matéria pouco atraente dependendo de como é ensinada. Essa questão é veementemente assinalada nos trechos anteriores. "O ensino de Biologia se organiza ainda hoje de modo a privilegiar o estudo de conceitos, linguagem e metodologias desse campo do conhecimento, tornando as aprendizagens pouco eficientes para interpretação e intervenção na realidade" (BORGES e LIMA, 2007, p.166). Mais do que fornecer somente informações, é imprescindível que o ensino de Biologia possibilite o desenvolvimento de competências que permitam ao aluno lidar com as informações, compreendê-las e elaborá-las, a fim de compreender o mundo e nele ser capaz de agir com autonomia (BRASIL, 2000). Espera-se que a formação biológica contribua para que cada indivíduo seja capaz de entender e aprofundar as explicações de processos e conceitos biológicos, sendo capaz de usar o que aprendeu quando tiver que tomar decisões de interesse individual e coletivo (KRASILCHIK, 2004). Tal perspectiva é perceptível nos trechos seguintes:

Foram apresentados temas importantes [...]. Esses itens são coisas que acontecem na nossa vida e dependemos deles.

Muito interessante! Pois ensinou o funcionamento dos lactobacilos no intestino [...]. Eles realmente são heróis no nosso organismo!!

É legal explicar temas como esses através de algo mais concreto, coisas que acontecem frequentemente nas nossas vidas. Através de explicações como essas é que podemos compreender cada vez mais as reações e as mudanças ocorridas dentro de nossos organismos [...]

Eu achei interessante porque às vezes a gente fica com medo de fazer [...], comer algumas coisas que na verdade nem fazem mal algum pra nós.

De acordo com os Parâmetros Curriculares Nacionais para o Ensino Médio (BRASIL, 2000), a proposta pedagógica das Ciências da Natureza, Matemática e suas Tecnologias objetiva a constituição de habilidades e competências que permitam ao educando, entre outras práticas, apropriar-se dos conhecimentos adquiridos na Física, na Química e na Biologia, aplicando-os com a finalidade de explicar o funcionamento do mundo natural, planejar, executar e 
avaliar ações de intervenção na realidade natural. Por outro lado, os PCNs relatam, em relação à Química, o seguinte:

\footnotetext{
Pesquisa recente com jovens de Ensino Médio revelou que estes não veem nenhuma relação da Química com suas vidas nem com a sociedade, como se o iogurte, os produtos de higiene pessoal e limpeza, os agrotóxicos ou as fibras sintéticas de suas roupas fossem questões de outra esfera de conhecimento, divorciadas da Química que estudam na escola. No caso desses jovens, a Química aprendida na escola foi transposta do contexto de sua produção original, sem que pontes tivessem sido feitas para contextos que são próximos e significativos. (BRASIL, 2000, p.79)
}

Tal constatação encontra-se de forma explícita nos dois últimos comentários expostos pelos alunos.

No que se refere à interseção entre as disciplinas pontuadas no artigo a Biologia e a Química - como importantes para este estudo, Júnior (2007) lembra que a Bioquímica representa uma área interdisciplinar entre elas, uma vez que possui como base as Ciências Biológicas e Químicas. Assim, constitui-se num eixo temático muito rico e promissor para abordagens interdisciplinares. Segundo Siqueira e Pereira (2010), o processo de integração recíproca entre disciplinas e/ou campos de conhecimento distintos - como a Química e a Biologia, por exemplo - podem romper as estruturas de cada uma delas para alcançar uma visão unitária do saber. "Nesse processo, os conteúdos das disciplinas devem ser trabalhados de tal forma que sirvam de aporte às outras, formando uma teia de conhecimentos" (GARRUTI e SANTOS, 2004, p.189). De acordo com Garruti e Santos (2004), é fundamental a criação de práticas de ensino que visem ao estabelecimento de relações entre as diversas disciplinas e que se aliem aos problemas da sociedade.

\section{CONSIDERAÇÕES FINAIS}

O uso de métodos de ensino alternativos, como as analogias, favorece a mobilização e reorganização de ideias prévias dos alunos que podem ser aplicadas aos novos conceitos abordados em sala de aula. Esses métodos têm facilitado o entendimento de conceitos científicos que, por vezes, se apresentam de forma complicada e pouco didática (pouco didatizada) aos alunos do Ensino Médio. A partir de nossas constatações, acreditamos que o uso de analogias, acompanhado das explicitações necessárias bem como do apontamento das limitações do processo de comparação entre os dois domínios (alvo e analógico), conduz a resultados favoráveis em termos da aprendizagem. Nos dois domínios, alvo e analógico, procuramos abordar relações de estrutura-função em sua dinamicidade e de modo articulado com necessidades e situações cotidianas. Dessa maneira, cremos que a ExpoBioquimica e atividades similares favorecem a mobilização de conhecimentos científicos em conexão com a realidade vivida, contribuindo, dessa maneira para a aprendizagem significativa e socioculturalmente relevante. 
Jéssica U1isses Barbosa|Murilo Cruz Leal|Samue1 Quinaud Rossi|

Tamara Nayara Dias | Karla Aparecida Ferreira | Cristiane Pereira de Oliveira

\section{BIBLIOGRAFIA}

ANDRADE, B. L.; ZYLLBERSZTAJN, A.; FERRARI, N. Analogias e metáforas no ensino de ciências à luz da epistemologia de Gaston Bachelard. Ensaio - Pesquisa em Educação em Ciências, Belo Horizonte, v.2, nº 2, p.231- 245, 2000.

BARDIN, L. Análise de conteúdo. Lisboa: Edições 70, 1977.

BORGES, R. M. R.; LIMA, V. M. R. Tendências contemporâneas do ensino de Biologia no Brasil. Revista Electrónica de Enseñanza de las Ciencia, v. 6, nº 1, p. 165-175, 2007. Disponível em: <http://reec.uvigo.es/volumenes/volumen6/ART10_Vol6_N1.pdf>. Acesso em: 01/02/2010.

BRASIL. Ministério da Educação, Secretaria de Educação Média e Tecnológica. Parâmetros Curriculares Nacionais: Ensino Médio. Brasília: Ministério da Educação, 2000.

CAFFAGNI, C. W. A.; MARANDINO, M. O uso de analogias e metáforas no discurso de monitores em museus de ciências. USP, 2010. Disponível em: < http://cmapspublic2. ihmc.us/rid.../Anex6_PrjCaffagni_050607.pdf>. Acesso em: 01/02/2010.

CARMO, E. A. Analogias como instrumentos úteis para o ensino do conteúdo químico no nivel médio. Belém: UFPA, 2006.

CONN, E. E.; STUMPF, P. K. Introducão a bioquímica. 4 ed. São Paulo: Edgard Blücher, 1980.

DUARTE, M. C. Analogias na educação em ciências: contributos e desafios. Investigações em Ensino de Ciências, Porto Alegre, v. 10, p. 7-29, 2005.

DUIT, R. On the role of analogies ad metaphors in learning science. Science Education, v. 75, n.6, p- 649 - 672, 1991.

FERRAZ, D. F.; TERRAZAN, E. A. Uso espontâneo de analogias por professores de biologia e o uso sistematizado de analogias: que relação? Ciência e Educação, v.9, n.2, p. 213-227, 2003.

FIGUEROA, A. M. S.; NAGEM, R. L.; CARVALHO, E. M. Metodologia de ensino com analogias: um estudo sobre a classificação dos animais. Encontro Nacional de pesquisa em educação em ciências, 4.,2003.Bauru. Anais eletrônicos... Bauru: ENPEC, 2003 Disponível em: <http://www.rieoei.org/deloslectores/842Senac.PDF>. Acesso em: 01/05/2010.

FREITAS, A. L. P. Bioquímica: do cotidiano para as salas de aula. Centro de Biotecnologia Molecular Estrutural - CBME InFormação, n.11, 2006. Disponível em: < http:/ cbme.usp. br/cbme/index.php/news_site/sala_dos_professores/reportagens_entrevistas_e_artigos/educacao_e_difusao_de_ciencia/bioquimica_do_cotidiano_para_as_salas_de_aula >. Acesso em: 23/03/2010.

GARRUTTI, E. A., SANTOS, S. R. A interdisciplinaridade como forma de superar a fragmentação do conhecimento. Revista de Iniciação Científica da FFC, v. 4, n. 2, 2004.

HOFFMANN, M. B., SCHEID,N. M. J. Analogias como ferramenta didática no ensino de biologia. Ensaio Pesquisa em Educação em Ciências, Belo Horizonte, v. 9, n.1, p. 1-17, 2007. Disponivel em: < www.portal.fae.ufmg.br/seer/index.php/ensaio/article/viewFile/118/ 16>8. Acesso em: 03/02/2010.

JÚNIOR, W. E. F. Bioquímica no ensino médio?! (de)limitações a partir da análise de alguns livros didáticos de química. Ciência e Ensino, v.1, n.2, 2007.

KRASILCHIK, M. Prática de ensino de biologia. São Paulo: Editora da Universidade de São Paulo, 2004. 
LIMA, K. E. C.; VASCONCELOS, S. D. Análise da metodologia de ensino de ciências nas escolas da rede municipal de Recife. Ensaio: Avaliação e Políticas Públicas em Educação, Rio de Janeiro, v.14, n.52, p. 397-412, 2006.

LEHNINGER, A L.; NELSON, D.L.; COX, M.M. Princípios de Bioquímica. 3.ed. São Paulo: Sarvier, 2002.

LOGUERCIO, R.; SOUZA, D.; DEL PINO, J. C. Mapeando a educação em bioquímica no Brasil. Ciências \& Cognição, Rio de Janeiro, v. 10, p. 147-155, 2007. Disponível em: < www.cienciasecognicao.org/pdf/v10/m346126.pdf>. Acesso em: 23/06/2010.

MACHADO, M.S. et al. Bioquímica através da animação. Florianópolis: UFSC, 2010. Disponível em: <www.periodicos.ufsc.br/index.php/extensio/article/.../1081/4358> Acesso em: 23/06/2010.

MARCONDES, M. I. Disciplinas e integração curricular: história e políticas. Educação \& Sociedade, Campinas, v. 23, n. 81, p. 293-298, 2002. Disponível em: < http:/ /www.cedes.unicamp.br>. Acesso em: 10/08/09.

MARTINS, I.; GOUVÊA,G.; PICCININI,C. Aprendendo com imagens. Revista da Sociedade Brasileira para o Progresso da Ciência, ano 57, n.4, p.38-40, 2005.

MENDONÇA, P. C. C.; JUSTI, R. S.; FERREIRA, P. F. M. Analogias usadas no ensino de equilíbrio químico: compreensões dos alunos e papel na aprendizagem. Revista Electrónica de Enseñanza de las Ciencia. Número extra, p. 1 a 4, 2005.

MONTEIRO, I.; JUSTI, R. Analogias em livros didáticos de química brasileiros destinados ao ensino médio. Investigações em ensino de Ciências. v.5, n. 2, p.1-24, 2000. Disponível em: <http://www.if.ufrgs.br/public/ensino>. Acesso em: 12/02/2010.

MOREIRA, M. A. Mapas conceituais e aprendizagem significativa. Porto Alegre: UFRGS, 1997. Disponível em: < http://omnis.if.ufrj.br/ marta/aprendizagememfisica/mapasconceituais.pdf $>$. Acesso em: 01/05/2010.

NUNES, R. R.; FERRAZ, D. F.; JUSTINA, L. A. D. Estudos relativos a analogias no ensino de ciências. In: JUSTINA, L. A. D.; FERRAZ, D. F. (Org.). Coleção Biologia em Foco 1: Conbecimentos Biológicos e Ensino de Ciências e Biologia. $1^{\text {a }}$ ed. Cascavel: Edunioeste, v. 1, p. 2336, 2009.

PÁDUA, I. C. A. Analogias, metáforas e a construção do conbecimento: por um processo ensino-prendizagem mais significativo. Pontíficia Universidade Católica (MG), 2010. Disponível em: $<$ http://www.anped.org.br/reunioes/26/.../isabelcamposaraujopadua.rtf $>$. Acesso em: 04/02/2010.

PERRELLI, M. A. S. Metáforas como objeto em ensino de ciências. Florianópolis: Universidade Federal de Santa Catarina, 1994.

QUADRADO, R. P., RIBEIRO, P. R. C. O corpo na escola: alguns olhares sobre o currículo. Revista Electrónica de Enseñanza de las Ciencia, n. extra, p. 1-4, 2005. Disponível em: <http://ensciencias.uab.es/webblues/www/.../2.../Quadrado_040.pdf>. Acesso em: 01/07/2009.

SILVA, L. L.; TERRAZAN, E. A. O uso de analogias no ensino de modelos atômicos. In: Simpósio nacional de ensino e física, 16.,2005. Rio de Janeiro. Anais eletrônicos... Rio de Janeiro:SBFísica, 2005. Disponível em: <http://www.sbf1.sbfisica.org.br/eventos/snef/ 
Jéssica U1isses Barbosa|Murilo Cruz Lea1| Samue1 Quinaud Rossi|

Tamara Nayara Dias | Karla Aparecida Ferreira | Cristiane Pereira de Oliveira

xvi/cd/.../T0666-1.pdf>. Acesso em: 03/02/2010.

SIQUEIRA, H. S. G., PEREIRA, M. A. A Interdisciplinaridade como superação da fragmentação. Santa Maria: UFSM, 2010. Disponível em: <http://www.angelfire.com/sk/holgonsi/interdiscip3.html>. Acesso em: 05/02/2010.

Data de recebimento: 19/07/2010

Data de aprovação: 08/10/2011

Data da versão final: 17/10/2011 